\section{Cureus}

\title{
Anal Melanoma in an Elderly Woman Masquerading as Hemorrhoid
}

Gabriel O. Ologun ${ }^{1}$, Yuan Stevenson ${ }^{1}$, Alice Shen ${ }^{1}$, Navpreet K. Rana ${ }^{1}$, Amber Hussain ${ }^{1}$, David Bertsch $^{2}$, Burt Cagir ${ }^{3}$

1. General Surgery, Robert Packer Hospital/Guthrie Clinic 2 . Surgical Oncology, Robert Packer Hospital/Guthrie Clinic 3. Colorectal Surgery, Robert Packer Hospital/Guthrie Clinic

$\square$ Corresponding author: Gabriel O. Ologun, gabe.ologun@gmail.com

Disclosures can be found in Additional Information at the end of the article

\section{Abstract}

Anal melanoma is a rare and aggressive neoplasm of the anal canal seen in the elderly population in the six or seventh decade of their lives. Presentation is usually nonspecific and diagnosis is often delayed or missed initially. The management is surgical and prognosis is poor. Here we present a case of anal melanoma in an elderly patient masquerading as hemorrhoid.

Categories: Oncology, Family/General Practice, General Surgery

Keywords: anus, melanoma, surgery, wide local excision, abdominoperineal resection, transanal excision

\section{Introduction}

Anal melanoma is a rare and aggressive neoplasm of the anal canal, comprised about $2 \%$ of anal neoplasm cases identified using the Surveillance Epidemiology and End Results (SEER) registry [1]. Females are more likely to be affected than males and most patients present in the sixth or seventh decade of their lives [2]. Patients typically present with nonspecific symptoms of rectal bleeding, pruritus, pain, and anorectal mass that mimics other benign conditions such as hemorrhoid, rectal polyp, rectal prolapse, resulting in misdiagnosis or delay in diagnosis with an average duration of symptoms before diagnosis between four and six months $[3,4]$. Here we present a case of anal melanoma in an elderly patient masquerading as hemorrhoid. Informed consent was obtained for the case report, images, and for publication.

\section{Case Presentation}

Received 11/17/2017

Review began 11/22/2017

Review ended 11/22/2017

Published 11/26/2017

\section{(c) Copyright 2017}

Ologun et al. This is an open access article distributed under the terms of the Creative Commons Attribution License CC-BY 3.0., which permits unrestricted use, distribution, and reproduction in any medium, provided the original author and source are credited.
An 88-year-old woman with history of hypertension, hyperlipidemia, coronary artery disease, constipation, sedentary was referred by her primary care provider to an outside general surgery clinic with diagnosis of bleeding hemorrhoid. The patient had four weeks history of anal discomfort with defecation, sensation of protruding mass in the anal region and intermittent bleeding from her anus. No prior colonoscopy. Evaluation of the anus at that time revealed a prolapsing purple-black mass below the dentate line thought to be a thrombosed hemorrhoid. Local excision was recommended at that time however patient and daughter declined surgery because her pain had been improving and her bowel habits had been regular. She would consider surgical intervention if her symptoms got worse.

The patient presented, 10 weeks later, to an outside emergency department with a complaint of enlarging perianal mass and pain, worse with seating. Surgical service was consulted. On exam she was noted to have a necrotic appearing pigmented lobulated anal mass measuring 7 


\section{Cureus}

$\mathrm{cm} \times 5 \mathrm{~cm}$. Biopsy was obtained and the patient was admitted to the surgical service. The result of the biopsy revealed malignant melanoma, ulcerated, invasive to a depth of $4.1 \mathrm{~mm}$. She was then transferred to our hospital for management. Computed tomography (CT) scan of the chest, abdomen and pelvis with contrast showed perianal mass with left inguinal lymphadenopathy. The patient and daughter opt for palliative management. She was taken to the operating room and underwent exam under anesthesia, and a palliative wide local excision (WLE) was performed. The total excised tissue was $7.3 \mathrm{~cm}$ x $6.2 \mathrm{~cm}$ x $2.7 \mathrm{~cm}$ irregular dark brown mass (Figure 1).

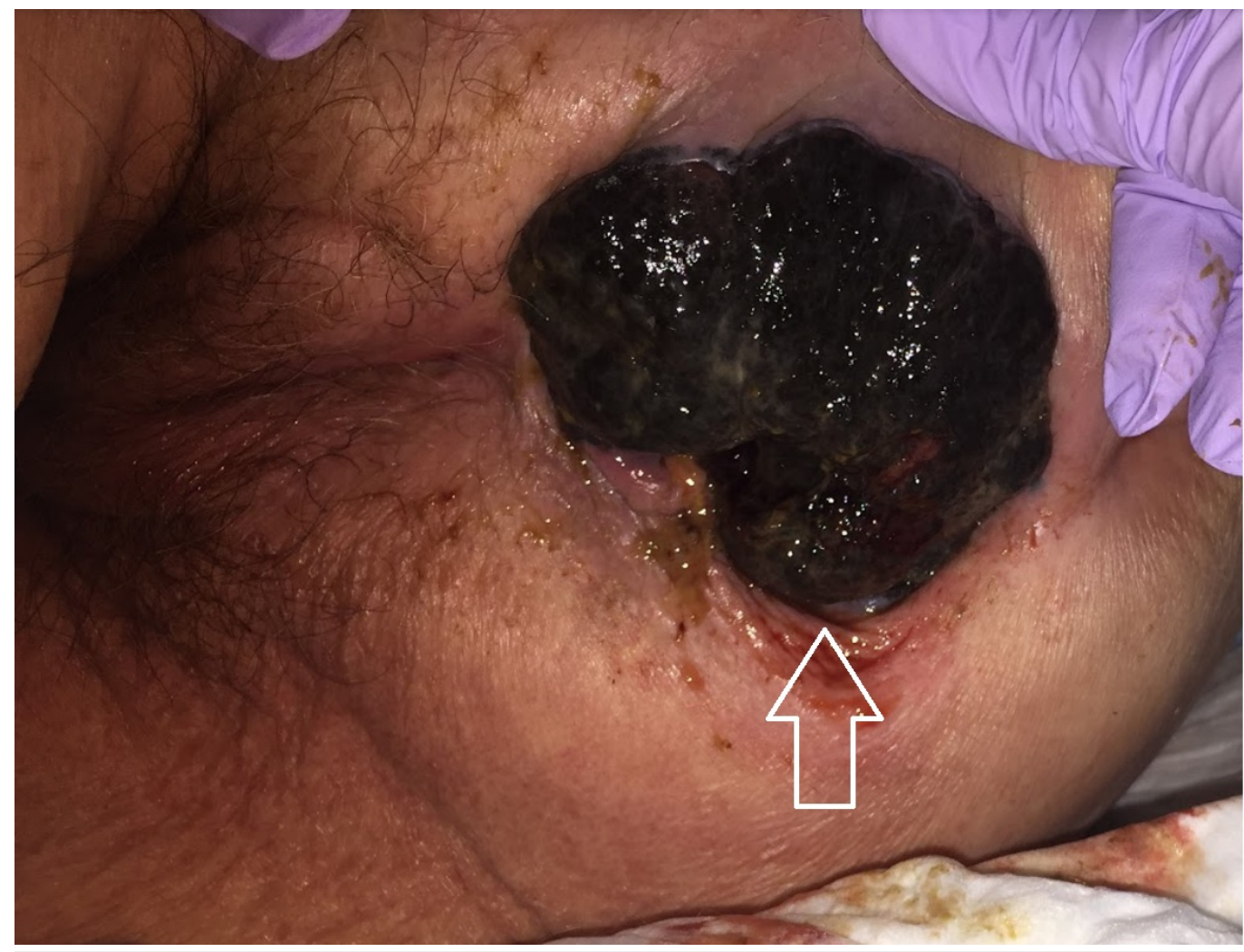

FIGURE 1: Anal melanoma (arrow).

Pathologic examination revealed malignant melanoma, invasive to a depth of at least $19 \mathrm{~mm}$, with extensive lymphovascular invasion and tumor involving the deep and radial margins of the specimen. She recovered well from the surgery, and was discharged to her personal home care facility on postoperative day three with home hospice care.

\section{Discussion}

The prognosis for anal melanoma is poor, with overall five-year survival rate of $10-20 \%[5,6]$, with a median survival of less than 20 months [3]. Hence any atypical anorectal lesion should be biopsied in order to prevent delay in diagnosis [6].

About 20\% of patients with newly diagnosed anal melanoma have lymph node-positive disease in the inguinal region [3]. The proportion of patients with systemic metastasis at presentation ranges from $7 \%$ to $25 \%$ [3]. Immunohistochemical staining can be useful in workup of a suspicious anorectal lesion. Melanoma is positive for S-100 protein, HMB-45, and vimentin. It is negative for carcinoembryonic antigen (CEA), cytokeratin, and epithelial membrane antigen. In patients diagnosed with anal melanoma, it is reasonable to rule systemic disease by 
evaluating with CT scan of head, chest, abdomen and pelvis [3].

The management of anal melanoma traditionally has included abdominoperineal resection (APR). However, there has been a trend in favor of less aggressive WLE due to the high morbidity of APR and perceived lack of survival benefit $[3,6]$.

Survival after WLE is similar to abdominoperineal resection, which has prompted tertiary oncology centers to recommend transanal excision over radical surgery in most cases. The result of systemic therapy for anal melanoma is disappointing. Radiation alone provides the option of sphincter preservation but does not increase survival $[3,6,7]$.

\section{Conclusions}

Anal melanomas continue to be diagnostic challenge due to their nonspecific symptoms making early diagnosis extremely difficult. Early diagnosis and early surgical intervention are imperative. It is associated with poor prognosis, regardless of the type of intervention used. The most important role of the surgeon may be palliation of symptoms.

\section{Additional Information}

\section{Disclosures}

Human subjects: Consent was obtained by all participants in this study. Conflicts of interest: In compliance with the ICMJE uniform disclosure form, all authors declare the following:

Payment/services info: All authors have declared that no financial support was received from any organization for the submitted work. Financial relationships: All authors have declared that they have no financial relationships at present or within the previous three years with any organizations that might have an interest in the submitted work. Other relationships: All authors have declared that there are no other relationships or activities that could appear to have influenced the submitted work.

\section{References}

1. Metildi C, McLemore EC, Tran T, et al.: Incidence and survival patterns of rare anal canal neoplasms using the surveillance epidemiology and end results registry. Am Surg. 2013, 79:1068-1074.

2. Wanebo HJ, Woodruff JM, Farr GH, et al.: Anorectal melanoma. Cancer. 1981, 47:1891-1900. 10.1002/1097-0142(19810401)47:7<1891::AID-CNCR2820470730>3.0.CO;2-K

3. Meguerditchian AN, Meterissian SH, Dun KB: Anorectal melanoma: diagnosis and treatment. Dis Colon Rectum. 2011, 54:638-644. 10.1007/DCR.0b013e31820c9b1b

4. Pessaux P, Pocard M, Elias D, et al.: Surgical management of primary anorectal melanoma . Br J Surg. 2004, 91:1183-1187. 10.1002/bjs.4592

5. van't Riet M, Giard RWM, de Wilt JHW, et al.: Melanoma of the anus disguised as hemorrhoids: surgical management illustrated by a case report. Dig Dis Sci. 2007, 52:17451747. 10.1007/s10620-006-9485-6

6. Iddings DM, Fleisig AJ, Chen SL, et al.: Practice pattern and outcome for anorectal melanoma in the USA, reviewing three decades of treatment: is more extensive surgical resection beneficial in all patients?. Ann Surg Oncol. 2010, 17:40-44. 10.1245/s10434-009-0705-0

7. Yeh JJ, Shia J, Hwu WJ, et al.: The role of abdominoperineal resection as surgical therapy for anorectal melanoma. Ann Surg. 2006, 244:1012-1017. 10.1097/01.sla.0000225114.56565.f9 